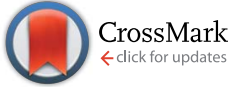

Cite this: Chem. Sci., 2015, 6, 4594

\title{
Cobalt diselenide nanobelts grafted on carbon fiber felt: an efficient and robust 3D cathode for hydrogen production $\uparrow$
}

\author{
Ya-Rong Zheng, \$ Min-Rui Gao, \$ Zi-You Yu, Qiang Gao, Huai-Ling Gao \\ and Shu-Hong Yu*
}

Design and fabrication of low-cost, highly efficient and robust three-dimensional (3D) hierarchical structure materials for electrochemical reduction of water to make molecular hydrogen is of paramount importance for real water splitting applications. Herein, a 3D hydrogen evolution cathode constructed by in situ growing of cobalt diselenide nanobelts on the surface of commercial carbon fiber felt shows exceptionally high catalytic activity with $141 \mathrm{mV}$ overpotential to afford a current density of $10 \mathrm{~mA} \mathrm{~cm}{ }^{-2}$, and a high exchange current density of $5.9 \times 10^{-2} \mathrm{~mA} \mathrm{~cm}^{-2}$. Remarkably, it also exhibits excellent catalytic stability, and could be used for more than 30000 potential cycles with no decrease in the current density in $0.5 \mathrm{M} \mathrm{H}_{2} \mathrm{SO}_{4}$. This easily prepared 3D material with excellent electrocatalytic performance is promising as a realistic hydrogen evolution electrode.

Received 14th April 2015

Accepted 18th May 2015

DOI: $10.1039 / c 5 s c 01335 f$

www.rsc.org/chemicalscience

In the past years, we have explored new catalysts from TMCs

\section{Introduction}

As a progressive energy carrier, $\mathrm{H}_{2}$ has attracted tremendous attention due to its potential as an alternative to fossil fuels. ${ }^{1,2}$ Currently, global hydrogen production mostly relies on natural gas, oil and coal, only a tiny part is from water electrolysis. ${ }^{3}$ Hence, energetically developing solar energy water splitting is critical for large-scale hydrogen technology. Hydrogen evolution reaction (HER) is a key process in photo/electrochemical water splitting, which needs an efficient and robust catalyst. ${ }^{4}$ Currently, platinum-based materials are the best HER catalysts, while the high-cost and scarcity of Pt heavily hinder its widespread use. ${ }^{5}$ Numerous efforts have been devoted to develop alternative HER electrocatalysts so far, including transitionmetal chalcogenides (TMCs), ${ }^{6-8}$ phosphates, ${ }^{9,10}$ carbides, ${ }^{11,12}$ nitrides, ${ }^{13-15}$ and molecular catalysts, ${ }^{16,17}$ also some 3D HER electrodes such as molybdenum disulfide $\left(\mathrm{MoS}_{2}\right)$ /fluorinedoped tin oxide, ${ }^{18} \mathrm{MoS}_{x} /$ graphene protected $\mathrm{Ni}$ foams,${ }^{19}$ and $\mathrm{CoSe}_{2}$ nanoparticles (NPs) grown on carbon paper. ${ }^{20}$ Despite significant progress, preparing active, stable and cheap HER electrode materials remains a big challenge.

Division of Nanomaterials and Chemistry, Hefei National Laboratory for Physical Sciences at Microscale, Collaborative Innovation Center of Suzhou Nano Science and Technology, Department of Chemistry, Institution University of Science and Technology of China, Hefei, Anhui, 230026, P. R. China. E-mail: shyu@ustc.edu.cn

$\dagger$ Electronic supplementary information (ESI) available: Experimental section, characterization, electrocatalytic study, and comparison of the literature catalytic parameters of various non-noble 3D HER electrocatalysts. See DOI: 10.1039/c5sc01335f

¥ Ya-Rong Zheng and Min-Rui Gao contributed equally to this work. and found that some TMCs possess decent HER and oxygen evolution reaction (OER) activities. ${ }^{21-24}$ Among which mesostructured $\mathrm{CoSe}_{2} /$ DETA (DETA $=$ diethylenetriamine) NBs and resultant hybrid materials exhibit high catalytic performances for both HER and OER. Very recently, we found that the HER activity and stability of $\mathrm{CoSe}_{2}$ NBs can be greatly enhanced after coating $\mathrm{MoS}_{2}$ on their surface due to the strong synergistic effect and increased catalytic sites. ${ }^{25}$ Therefore, as a multifunctional catalyst and an excellent substrate material, integrating the individual $2 \mathrm{D} \mathrm{CoSe} \mathrm{CB}_{2} \mathrm{NBs}$ into a macroscopic 3D structure is of significant importance for practical application in energy conversion systems. Carbon fiber felt (CFF) has been used as the support material, due to the excellent mechanical strength, high conductivity, light-weight 3D structure, good corrosion resistance in harsh conditions, and large specific surface area as well as conductivity for intermediation transport. ${ }^{26-30}$

Herein, we report an economic, facile, and easily scaled-up method to prepare a $\mathrm{CoSe}_{2}$ NBs grafted CFF 3D architecture electrode (denoted as $\mathrm{CoSe}_{2} / \mathrm{CFF}$ ). Remarkably, the 3D $\mathrm{CoSe}_{2} /$ CFF electrode exhibits an extremely high stability under acidic conditions with a small onset potential of $96 \mathrm{mV} v s$. RHE, a Tafel slope of $68 \mathrm{mV}$ per decade, and a large exchange current density of $5.9 \times 10^{-2} \mathrm{~mA} \mathrm{~cm}^{-2}$, which outperforms those of a nanostructured $\mathrm{MoS}_{2}$ catalyst, ${ }^{8} \mathrm{MoS}_{2} /$ graphene hybrid, ${ }^{31}$ and other common non-precious metal catalysts. ${ }^{32-34}$ All these results strongly demonstrate the promise of a cheap, efficient and robust HER cathode based on $\mathrm{CoSe}_{2} / \mathrm{CFF}$ material. 


\section{Results and discussion}

The porous commercial 3D CFF consists of $\sim 10 \mu \mathrm{m}$ carbon fibers with a highly textured surface (ESI, Fig. S1 $\dagger$ ), and the carbon fibers (prepared by thermal treatment of polyacrylonitrile fibers) have a number of functional groups such as $-\mathrm{COOH},-\mathrm{CO}$, and -CN (Fig. S2 $\dagger$ ), which would be beneficial for nucleation and growth of the $\mathrm{CoSe}_{2} \mathrm{NBs}$ due to the strong chemical adhesion. The $3 \mathrm{D} \mathrm{CoSe}_{2} / \mathrm{CFF}$ was synthesized by a one-step method in a closed solvothermal system (Fig. 1a). The phase of the prepared $\mathrm{CoSe}_{2} / \mathrm{CFF}$ composite is characterized by $\mathrm{X}$-ray diffraction (XRD), as shown in Fig. 1b. It is observed that the diffraction peaks of the $\mathrm{CoSe}_{2} / \mathrm{CFF}$ composite are at $34.2^{\circ}$, $46.4^{\circ}, 51.7^{\circ}$, and $63.4^{\circ}$, which were indexed to the (210), (221), (311), and (400) reflections of cubic phase $\mathrm{CoSe}_{2}$ (JCPDS card no. 09-0234), respectively. Other diffraction peaks of $\mathrm{CoSe}_{2}$ are hard to distinguish due to the relatively weak diffraction intensity and low amount compared to the CFF substrate. The peaks at $26.4^{\circ}$ and $43.9^{\circ}$ indicate graphitized carbon content of the CFF substrate.

Fig. 2a shows a low magnification scanning electron microscopy (SEM) image of the $\mathrm{CoSe}_{2} / \mathrm{CFF}$ composite, which reveals that the entire surface of the CFF was uniformly covered by the densely packed $\mathrm{CoSe}_{2} \mathrm{NBs}$. By tuning the ratio of the raw materials and changing the volume of the reaction system, we can obtain different loading amounts from $4.37-22.43 \mathrm{wt} \%$ and various sizes $\left(1-75 \mathrm{~cm}^{2}\right.$ ) of $\mathrm{CoSe}_{2} / \mathrm{CFF}$ composites (Fig. S3 and $\mathrm{S} 4 \dagger)$. Through the SEM image of the low loading (8.17 wt\%) $\mathrm{CoSe}_{2} / \mathrm{CFF}$ composite, we find that the $\mathrm{CoSe}_{2}$ NBs with lengths of up to several micrometers and widths of $c a$. 200-800 $\mathrm{nm}$ are well grafted on the surface of the carbon fiber. It can be clearly seen that the grafted $\mathrm{CoSe}_{2} \mathrm{NBs}$ still maintain their original flexible belt-like morphology (Fig. S5†). Transmission electron microscopy (TEM) images of the decorated $\mathrm{CoSe}_{2}$ NBs show the ultrathin lamellar nanostructure of the packed $\mathrm{CoSe}_{2} \mathrm{NBs}$ (Fig. 2c and d), which would have advantages for the electro transform and the exchange of the intermediate during the catalytic reaction. ${ }^{35}$ The selected-area electron diffraction (SAED) pattern of the $\mathrm{CoSe}_{2}$ NBs (inset in Fig. 2c) shows the

a)

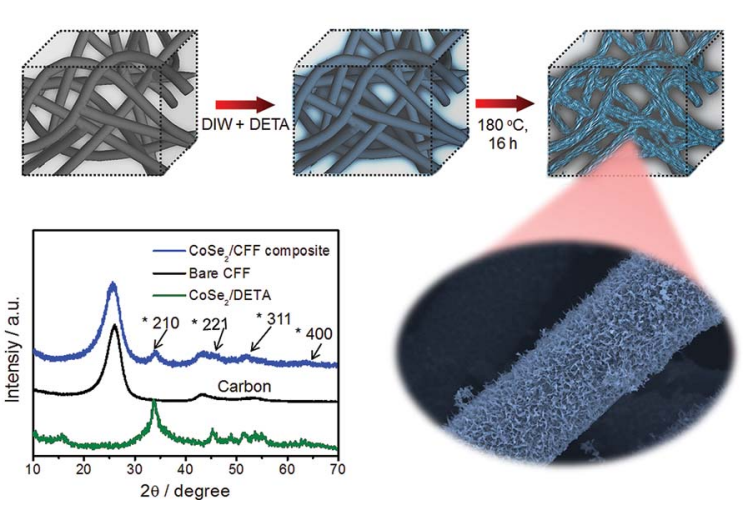

Fig. 1 (a) Schematic illustration of the preparation of the $\mathrm{CoSe}_{2} / \mathrm{CFF}$ composite; (b) XRD patterns of $\mathrm{CoSe}_{2} / \mathrm{DETA} \mathrm{NBs}$, bare CFF and the $\mathrm{CoSe}_{2} / \mathrm{CFF}$ composite. distinct diffraction spots index to the (400), (422) and (440) planes of the decorated $\mathrm{CoSe}_{2}$ NBs. The high resolution TEM (HRTEM) investigation in Fig. 2e shows the lattice fringe with a spacing of $2.65 \AA$ can be assigned to the (210) plane of cubic phase $\mathrm{CoSe}_{2}$. The ordered lamellar $\mathrm{CoSe}_{2}$ NBs are also observed in Fig. 2d. We found that the interlayer distance is ca. $0.95 \mathrm{~nm}$ (Fig. 2f), which corresponds to the original $\mathrm{CoSe}_{2} /$ DETA NBs. $^{36}$ Scanning TEM energy dispersive X-ray spectroscopy (STEMEDS) elemental mapping images of Co and Se for $\mathrm{CoSe}_{2} \mathrm{NBs}$ are shown in Fig. $2 \mathrm{~g}$, further revealing that both Co and Se elements are uniformly distributed on the carbon fiber. Additionally, the $\mathrm{CoSe}_{2} / \mathrm{CFF}$ composite was also investigated using energydispersive X-ray spectroscopy (EDS) and X-ray photoelectron spectroscopy (XPS) (Fig. S6 and S7†). The interface between the $\mathrm{CoSe}_{2} \mathrm{NBs}$ and CFF was detected in Fig. S8. $\dagger$ We found that fluffy nanosheets (NSs) were closely adhered on the CFF surface, and the dense $\mathrm{CoSe}_{2} \mathrm{NBs}$ are grown upon these NSs. We investigated the growth process of the $\mathrm{CoSe}_{2}$ NBs on the CFF surface (Fig. S9†). In the beginning stage, the adsorbed Co and Se raw materials started to grow into NSs on the surface of the CFF. As the growth continued, more NSs nucleated on the surface, and the pre-obtained NSs would keep growing into belt structures, as the growth mechanism of the individual $\mathrm{CoSe}_{2} /$

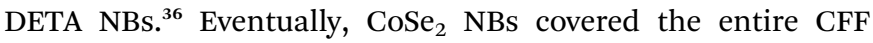
surface, while also maintaining the CFF 3D architecture.

The 3D $\mathrm{CoSe}_{2} / \mathrm{CFF}$ composite (loading amount: $8.17 \mathrm{wt} \%$ ) was directly investigated as the working electrode in a typical three-electrode system for HER in $0.5 \mathrm{M} \mathrm{H}_{2} \mathrm{SO}_{4}$. Bare CFF and the same loading $\mathrm{CoSe}_{2} \mathrm{NBs}$ and $\mathrm{CFF}$ physical mixture (denoted as $\mathrm{CoSe}_{2}$ \& CFF) samples were also tested for comparison. As

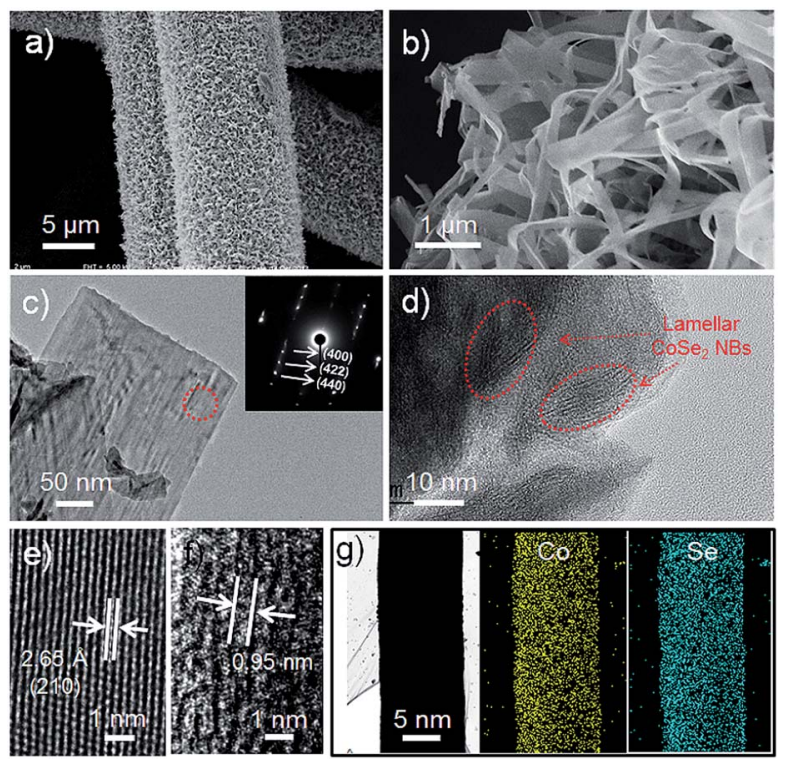

Fig. 2 (a) and (b) SEM images with different magnifications of $\mathrm{COSe}_{2}$ /CFF composite; (c) and (d) TEM images with different magnifications of the $\mathrm{COSe}_{2}$ NBs grafted on the surface of CFF. The inset in (c) shows the corresponding SAED pattern; (e) and (f) HRTEM images of the $\mathrm{COSe}_{2} / \mathrm{CFF}$ composite; (g) STEM-EDS elemental maps of $\mathrm{CoSe}_{2} / \mathrm{CFF}$ composite overlap, Co (yellow) and Se (blue), respectively. 
shown in Fig. 3a, the $\mathrm{CoSe}_{2}$ \& CFF mixture shows a larger onset potential due to the aggregation of active materials and poor connection between $\mathrm{CoSe}_{2}$ and CFF, suggesting that the purely physical blend could not essentially enhance the catalytic activity (Fig. S10 $\dagger$ ). In contrast, the $\mathrm{CoSe}_{2} / \mathrm{CFF}$ composite exhibits a lower onset potential of $96 \mathrm{mV}$ and greater cathodic current density. The overpotential of $\mathrm{CoSe}_{2} / \mathrm{CFF}$ required to drive the cathodic current density of $10 \mathrm{~mA} \mathrm{~cm}^{-2}$ is $141 \mathrm{mV}$, which is much lower than that of the $\mathrm{CoSe}_{2}$ \& CFF mixture (252 $\mathrm{mV})$. The bare CFF has poor HER activity in acidic solution. Additionally, the different loading catalysts suggest that the loading amount of $8.17 \mathrm{wt} \%$ is the optimal in this system (Fig. S11†).

The HER kinetics of the catalysts were probed by corresponding Tafel slopes (overpotential versus log current) (Fig. 3b). Under a specific set of conditions, the Tafel slopes of $\sim 120$, $\sim 40$, or $\sim 30 \mathrm{mV}$ per decade will be achieved if the Volmer, Heyrovsky, or Tafel step is the rate-determining step, respectively. The experimentally measured Tafel slope of $68 \mathrm{mV}$ per decade for the $\mathrm{CoSe}_{2} / \mathrm{CFF}$ composite indicates that the HER occurs by a Volmer-Heyrovsky mechanism. ${ }^{2,37}$ The strong chemical attachment and electrical coupling between the CFF and $\mathrm{CoSe}_{2}$ (Fig. S12 $\dagger$ ) enables an optimized electronic structure of $\mathrm{CoSe}_{2}$ upon its synergistic interaction with CFF that leads to faster HER kinetics. By contrast, a much higher Tafel slope of $123 \mathrm{mV}$ per decade was observed for the $\mathrm{CoSe}_{2}$ \& CFF mixture, which possibly stems from the fact that the active $\mathrm{CoSe}_{2}$ are just physically attached to the carbon fiber surface and thus no beneficial coupling effects were achieved. The HER catalyst inherent activity was further evaluated by the exchange current density $\left(j_{0}\right)$ based on the Tafel plot (Fig. S13†). As the key descriptor of the catalytic activity of an electrocatalyst, $j_{0}$ could profoundly reflect the intrinsic electrochemical reaction rate. ${ }^{38}$
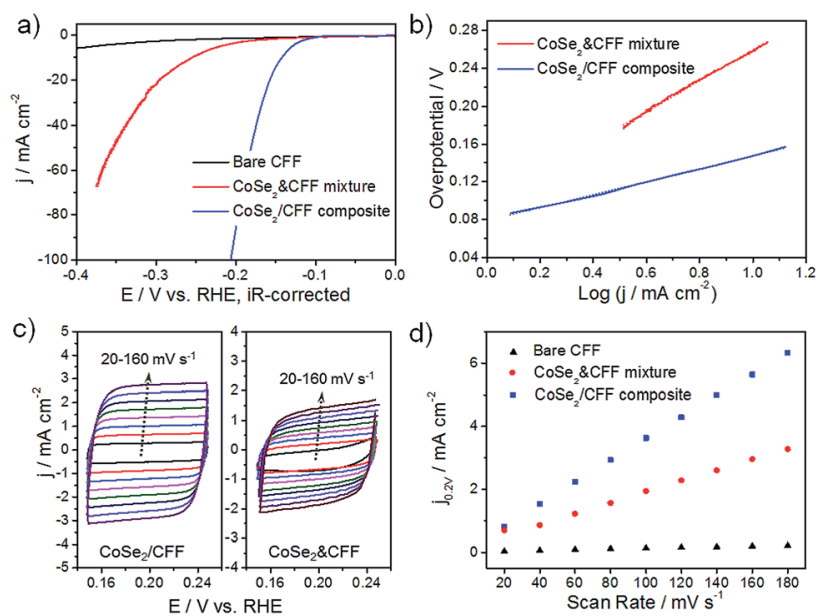

Fig. 3 Electrochemical performance of $\mathrm{CoSe}_{2} / \mathrm{CFF}$ electrode in $0.5 \mathrm{M}$ $\mathrm{H}_{2} \mathrm{SO}_{4}$. (a) iR-corrected polarization curves for HER on bare CFF, $\mathrm{COSe}_{2}$ \& CFF mixture and CoSe $/$ /CFF composite, respectively; (b) Tafel plots and (c) cyclic voltammograms for $\mathrm{CoSe}_{2} / \mathrm{CFF}$ composite and $\mathrm{CoSe}_{2} \&$ CFF mixture at different scan rates from 20 to $160 \mathrm{mV} \mathrm{s}^{-1}$, respectively; (d) the capacitive currents at $0.20 \mathrm{~V} v \mathrm{vs}$. RHE as a function of scan rate for $\mathrm{CoSe}_{2} \&$ CFF mixture and $\mathrm{CoSe}_{2} / \mathrm{CFF}$ composite.
The $j_{0}$ of $5.9 \times 10^{-2} \mathrm{~mA} \mathrm{~cm}^{-2}$ for $\mathrm{CoSe}_{2} / \mathrm{CFF}$ outperforms most non-noble 3D HER electrocatalysts (see ESI Table S1†). Using the cyclic voltammetry $(\mathrm{CV})$ method, we obtained the double layer capacitance $\left(C_{\mathrm{dl}}\right)$, which is considered as an alternative approach to estimate the effective surface area (Fig. $3 \mathrm{c}$ and d). ${ }^{33}$ The $C_{\mathrm{dl}}$ of $17.2 \mathrm{mF} \mathrm{cm}^{-2}$ of the $\mathrm{CoSe}_{2} / \mathrm{CFF}$ electrode is much larger than that of $\mathrm{CoSe}_{2} \& \mathrm{CFF}\left(8.4 \mathrm{mF} \mathrm{cm}^{-2}\right)$ and other reported 3D HER electrodes (Table S1†); pure CFF $(0.56 \mathrm{mF}$ $\mathrm{cm}^{-2}$ ) has negligible contribution to the capacitance. The reason is that for the $\mathrm{CoSe}_{2} / \mathrm{CFF}$ composite, active $\mathrm{CoSe}_{2}$ grafts uniformly onto every carbon fiber and forms a 3D architecture with advantageous holes, which allows better electrolyte and reactants/products transfer and thus a larger $C_{\mathrm{dl}}$ value. Since $C_{\mathrm{dl}}$ is proportional to the active surface area of the catalyst, the results suggest that the $\mathrm{CoSe}_{2} / \mathrm{CFF}$ is more effective in enlarging the catalytic surface area as compared to the $\mathrm{CoSe}_{2}$ \& CFF mixture, and thus leading to the superior HER activity. The enhanced electrode kinetic factors (small onset potential of $96 \mathrm{mV}$ and a Tafel slope of $68 \mathrm{mV}$ per decade), large $j_{0}$ of $5.9 \times$ $10^{-2} \mathrm{~mA} \mathrm{~cm}{ }^{-2}$ ( $\sim 1$ order of magnitude lower than that of $0.71 \mathrm{~mA} \mathrm{~cm}^{-2}$ for Pt) ${ }^{25}$ and low impedance (Fig. S14 $\dagger$ ) indicate that the markedly faster HER kinetics compare favorably to the behavior of other non-noble HER electrocatalysts in acidic electrolyte, including the $\mathrm{MoS}_{x} /$ graphene, ${ }^{19} \mathrm{CoSe}_{2}$ NPs/carbon paper, ${ }^{20}$ and Co-doped $\mathrm{FeS}_{2} /$ carbon nanotubes. ${ }^{39}$

High stability is a crucial factor for a good catalytic electrode. The accelerated durability tests (ADT) of $\mathrm{CoSe}_{2} / \mathrm{CFF}$ and $\mathrm{CoSe}_{2} \&$ CFF electrodes were measured by taking continuous potential cycling at $100 \mathrm{mV} \mathrm{s}^{-1}$ for 30000 cycles in $0.5 \mathrm{M} \mathrm{H}_{2} \mathrm{SO}_{4}$. As shown in Fig. 4a, the polarization curve of the $\mathrm{CoSe}_{2} / \mathrm{CFF}$ electrode after 30000 cycles has negligible loss of the cathodic current, and the overlays almost coincide to the initial one. While the same testing leads to a large loss for the $\mathrm{CoSe}_{2}$ \& CFF electrode. Compared with the chemically grafted $\mathrm{CoSe}_{2} / \mathrm{CFF}$ composite, $\mathrm{CoSe}_{2} \mathrm{NBs}$ in the $\mathrm{CoSe}_{2}$ \& $\mathrm{CFF}$ electrode are chaotically dispersed in the opening spaces of 3D CFF and physically attached to the CFF surface (Fig. S10 $\dagger$ ), which is more susceptible to suffering chemical corrosion during the ADT. Different loading $\mathrm{CoSe}_{2} / \mathrm{CFF}$ catalysts also have excellent stability in this system (Fig. S15†). In Fig. 4b, the time-dependent current density curves at fixed potentials also suggest the $\mathrm{CoSe}_{2} / \mathrm{CFF}$ electrode has superior durability over $24 \mathrm{~h}$. Fig. $4 \mathrm{c}$ and d show the SEM and TEM images of the $\mathrm{COSe}_{2} / \mathrm{CFF}$ after ADT; we found that the densely coated $\mathrm{CoSe}_{2}$ NBs still covered the CFF surface only with some aggregations. This suggests that the well-grafted $\mathrm{CoSe}_{2}$ on the CFF ensures the intimate contact and good chemical and mechanical adhesion, while the chemically resistant CFF can guarantee the advantageous 3D architecture. We therefore consider that the excellent stability of the $\mathrm{CoSe}_{2} / \mathrm{CFF}$ composite is contributed to by the strong chemical attachment of $\mathrm{CoSe}_{2}$ onto the porous 3D CFF that protects $\mathrm{CoSe}_{2}$ from growth, migration and aggregation during the continuous potential cycling process. STEM-EDS elemental map images indicate that Co and Se elements are still uniformly distributed on the CFF. XRD, EDS and XPS of the $\mathrm{CoSe}_{2} / \mathrm{CFF}$ after ADT were further employed to demonstrate the high durability of the $\mathrm{CoSe}_{2} / \mathrm{CFF}$ (Fig. S16 $\dagger$ ). 
a)
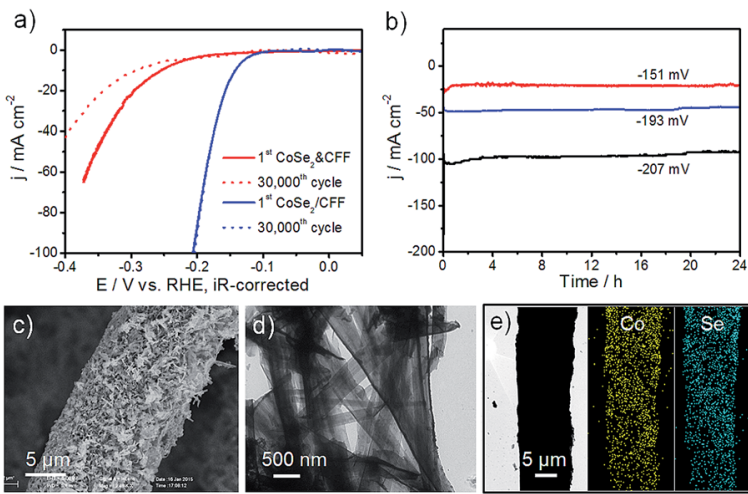

$500 \mathrm{~nm}$

Fig. 4 (a) ADT for $\mathrm{CoSe}_{2} \& \mathrm{CFF}$ and $\mathrm{CoSe}_{2} / \mathrm{CFF}$ electrodes before and after 30000 potential cycles in $0.5 \mathrm{M} \mathrm{H}_{2} \mathrm{SO}_{4}$; (b) chronopotentiometry curves of $\mathrm{CoSe}_{2} / \mathrm{CFF}$ electrode during electrolysis over $24 \mathrm{~h}$ at fixed overpotential of $-151,-193$, and $-207 \mathrm{mV}$ (after iR correction), respectively; (c) and (d) SEM and TEM images of $\mathrm{COSe}_{2} / \mathrm{CFF}$ after ADT; (e) STEM-EDS elemental maps of $\mathrm{CoSe}_{2} / \mathrm{CFF}$ after ADT, Co (yellow) and Se (blue), respectively.

It is interesting to understand the intrinsic reasons for the enhanced activity and durability of the $\mathrm{CoSe}_{2} / \mathrm{CFF}$. High-resolution Co 2p XPS spectra of individual $\mathrm{CoSe}_{2} /$ DETA NBs and $\mathrm{CoSe}_{2} / \mathrm{CFF}$ show a dramatically increased electro-binding energy $(\sim 0.9 \mathrm{eV})$ of Co $2 \mathrm{p}$ after growing $\mathrm{CoSe}_{2} \mathrm{NBs}$ on the CFF surface (Fig. S12 $\dagger$ ), suggesting the presence of charge-transfer between CFF and $\mathrm{CoSe}_{2} \mathrm{NBs}^{40}$ The densely grafted $\mathrm{CoSe}_{2} \mathrm{NBs}$ structure exposes more active sites, and the modified active site could sufficiently bond with adsorbed $\mathrm{H}^{*}$ (a key intermediate during HER) for accelerating the proton-electron-transfer process. ${ }^{38}$ Furthermore, the highly opened 3D pore structure could provide more accessible active sites for water dissociation and facilitate the release of the generated gaseous $\mathrm{H}_{2}$ from the electrode surface. Meanwhile, it could offer a robust connection within the entire framework, enabling easy contact with the electrolyte. ${ }^{41}$ The excellent corrosion resistance ability of carbon fiber and strong chemical bonding with $\mathrm{CoSe}_{2}$ ensure the stable activity during the potential cycling process due to the $3 \mathrm{D}$ wrapping effect of the carbon fiber. ${ }^{42}$ Considering the comprehensive factors of the cost-effectiveness, high activity and corrosion resistance, the $3 \mathrm{D} \mathrm{CoSe}_{2} / \mathrm{CFF}$ holds a promising prospect as a new HER cathode for large-scale hydrogen production.

\section{Conclusions}

In summary, we report a facile method to prepare a highly active, stable $3 \mathrm{D} \mathrm{CoSe}_{2} / \mathrm{CFF}$ hierarchical electrode, which is economic, facile and easily scaled-up. The prepared 3D $\mathrm{CoSe}_{2} / \mathrm{CFF}$ electrode is extremely robust and can be directly used as the HER cathode, which shows high activity for $\mathrm{H}_{2}$ evolution in acidic solution with an overpotential of $96 \mathrm{mV}$, Tafel slope of $68 \mathrm{mV}$ per decade and a high exchange current density of $5.9 \times 10^{-2} \mathrm{~mA} \mathrm{~cm}^{-2}$. The synergistic effect between $\mathrm{CoSe}_{2}$ and carbon fiber may contribute to the enhanced activity, and the 3D architecture framework leads to the high catalytic stability in the long-term operation. The easily prepared 3D $\mathrm{CoSe}_{2} / \mathrm{CFF}$ electrode holds a promise to replace the noble metal catalysts for electrochemical $\mathrm{H}_{2}$ production in viable water electrolytic systems.

\section{Acknowledgements}

This work is supported by the National Basic Research Program of China (Grants 2013CB933900, 2014CB931800), the National Natural Science Foundation of China (Grants 21431006, 91227103, 21061160492, J1030412), the Chinese Academy of Sciences (Grant KJZD-EW-M01-1), and Scientific Research Grant of Hefei Science Center of CAS (no. 2015SRG-HSC038).

\section{Notes and references}

1 M. S. Dresselhaus and I. L. Thomas, Nature, 2001, 414, 332337.

2 M. G. Walter, E. L. Warren, J. R. McKone, S. W. Boettcher, Q. X. Mi, E. A. Santori and N. S. Lewis, Chem. Rev., 2010, 110, 6446-6473.

3 T. R. Cook, D. K. Dogutan, S. Y. Reece, Y. Surendranath, T. S. Teets and D. G. Nocera, Chem. Rev., 2010, 110, 64746502.

4 J. Greeley, T. F. Jaramillo, J. Bonde, I. B. Chorkendorff and J. K. Norskov, Nat. Mater., 2006, 5, 909-913.

5 H. B. Gray, Nat. Chem., 2009, 1, 7.

6 M. R. Gao, Y. F. Xu, J. Jiang and S. H. Yu, Chem. Soc. Rev., 2013, 42, 2986-3017.

7 M. R. Gao, J. Jiang and S. H. Yu, Small, 2012, 8, 13-27.

8 T. F. Jaramillo, K. P. Jorgensen, J. Bonde, J. H. Nielsen, S. Horch and I. Chorkendorff, Science, 2007, 317, 100-102.

9 E. J. Popczun, J. R. McKone, C. G. Read, A. J. Biacchi, A. M. Wiltrout, N. S. Lewis and R. E. Schaak, J. Am. Chem. Soc., 2013, 135, 9267-9270.

10 J. Kibsgaard and T. F. Jaramillo, Angew. Chem., Int. Ed., 2014, 53, 14433-14437.

11 H. Vrubel and X. L. Hu, Angew. Chem., Int. Ed., 2012, 51, 12703-12706.

12 D. V. Esposito, S. T. Hunt, Y. C. Kimmel and J. G. G. Chen, J. Am. Chem. Soc., 2012, 134, 3025-3033.

13 W. F. Chen, K. Sasaki, C. Ma, A. I. Frenkel, N. Marinkovic, J. T. Muckerman, Y. M. Zhu and R. R. Adzic, Angew. Chem., Int. Ed., 2012, 51, 6131-6135.

14 Y. Zhao, F. Zhao, X. Wang, C. Xu, Z. Zhang, G. Shi and L. Qu, Angew. Chem., Int. Ed., 2014, 53, 13934-13939.

15 J. Duan, S. Chen, M. Jaroniec and S. Z. Qiao, ACS Nano, 2015, 9, 931-940.

16 M. J. Rose, H. B. Gray and J. R. Winkler, J. Am. Chem. Soc., 2012, 134, 8310-8313.

17 Y. J. Sun, J. P. Bigi, N. A. Piro, M. L. Tang, J. R. Long and C. J. Chang, J. Am. Chem. Soc., 2011, 133, 9212-9215.

18 J. C. Kibsgaard, Z. Chen, B. N. Reinecke and T. F. Jaramillo, Nat. Mater., 2012, 11, 963.

19 Y. H. Chang, C. T. Lin, T. Y. Chen, C. L. Hsu, Y. H. Lee, W. Zhang, K. H. Wei and L. J. Li, Adv. Mater., 2013, 25, 756-760. 
20 D. S. Kong, H. T. Wang, Z. Y. Lu and Y. Cui, J. Am. Chem. Soc., 2014, 136, 4897-4900.

21 M. R. Gao, Y. F. Xu, J. Jiang, Y. R. Zheng and S. H. Yu, J. Am. Chem. Soc., 2012, 134, 2930-2933.

22 M. R. Gao, Z. Y. Lin, T. T. Zhuang, J. Jiang, Y. F. Xu, Y. R. Zheng and S. H. Yu, J. Mater. Chem., 2012, 22, 1366213668.

23 Y. F. Xu, M. R. Gao, Y. R. Zheng, J. Jiang and S. H. Yu, Angew. Chem., Int. Ed., 2013, 52, 8546-8550.

24 M. R. Gao, X. Cao, Q. Gao, Y. F. Xu, Y. R. Zheng, J. Jiang and S. H. Yu, ACS Nano, 2014, 8, 3970-3978.

25 M.-R. Gao, J.-X. Liang, Y.-R. Zheng, Y.-F. Xu, J. Jiang, Q. Gao, J. Li and S.-H. Yu, Nat. Commun., 2015, 6, 5892.

26 M. Park, Y. J. Jung, J. Kim, H. I. Lee and J. Cho, Nano Lett., 2013, 13, 4833-4839.

27 W. H. Wang and X. D. Wang, Electrochim. Acta, 2007, 52, 6755-6762.

28 D. J. Suarez, Z. Gonzalez, C. Blanco, M. Granda, R. Menendez and R. Santamaria, ChemSusChem, 2014, 7, 914-918.

29 Z. X. He, L. Liu, C. Gao, Z. Zhou, X. X. Liang, Y. Lei, Z. He and S. Q. Liu, RSC Adv., 2013, 3, 19774-19777.

30 H. P. Cong, J. F. Chen and S. H. Yu, Chem. Soc. Rev., 2014, 43, 7295-7325.

31 Y. G. Li, H. L. Wang, L. M. Xie, Y. Y. Liang, G. S. Hong and H. J. Dai, J. Am. Chem. Soc., 2011, 133, 7296-7299.
32 Y. Ito, W. Cong, T. Fujita, Z. Tang and M. Chen, Angew. Chem., Int. Ed., 2014, 54, 2131-2136.

33 M. A. Lukowski, A. S. Daniel, F. Meng, A. Forticaux, L. S. Li and S. Jin, J. Am. Chem. Soc., 2013, 135, 10274-10277.

34 L. Cheng, W. Huang, Q. Gong, C. Liu, Z. Liu, Y. Li and H. Dai, Angew. Chem., Int. Ed., 2014, 53, 7860-7863.

35 Y. R. Zheng, M. R. Gao, Q. Gao, H. H. Li, J. Xu, Z. Y. Wu and S. H. Yu, Small, 2015, 11, 182-188.

36 M. R. Gao, W. T. Yao, H. B. Yao and S. H. Yu, J. Am. Chem. Soc., 2009, 131, 7486-7487.

37 M. R. Gao, S. R. Zhang, J. Jiang, Y. R. Zheng, D. Q. Tao and S. H. Yu, J. Mater. Chem., 2011, 21, 16888-16892.

38 Y. Zheng, Y. Jiao, M. Jaroniec and S. Z. Qiao, Angew. Chem., Int. Ed., 2015, 54, 52-65.

39 D. Y. Wang, M. Gong, H. L. Chou, C. J. Pan, H. A. Chen, Y. Wu, M. C. Lin, M. Guan, J. Yang, C. W. Chen, Y. L. Wang, B. J. Hwang, C. C. Chen and H. Dai, J. Am. Chem. Soc., 2015, 137, 1587-1592.

40 P. E. R. Blanchard, B. R. Slater, R. G. Cavell, A. Mar and A. P. Grosvenor, Solid State Sci., 2010, 12, 50-58.

41 S. Peng, L. Li, X. Han, W. Sun, M. Srinivasan, S. G. Mhaisalkar, F. Cheng, Q. Yan, J. Chen and S. Ramakrishna, Angew. Chem., Int. Ed., 2014, 53, 1259412599.

42 L. Miao, J. B. Wu, J. J. Jiang and P. Liang, J. Phys. Chem. C, 2013, 117, 23-27. 